\title{
The Effect of Cerium Oxide Addition on the Properties and Behavior of Y-TZP
}

\author{
D. Ragurajan, M. Satgunam, and M. Golieskardi \\ Department of Mechanical Engineering, Centre of Ceramic Technology, Universiti Tenaga Nasional, 43000 Kajang, Malaysia
}

Correspondence should be addressed to D. Ragurajan; dineshragurajan@gmail.com

Received 16 June 2014; Revised 28 August 2014; Accepted 2 September 2014; Published 30 October 2014

Academic Editor: Chantara Thevy Ratnam

Copyright (C) 2014 D. Ragurajan et al. This is an open access article distributed under the Creative Commons Attribution License, which permits unrestricted use, distribution, and reproduction in any medium, provided the original work is properly cited.

\begin{abstract}
The effects of $\mathrm{CeO}_{2}$ addition on the sintering behavior and mechanical properties of Y-TZP have been investigated over a wide sintering regime by pressureless sintering. It has been revealed that small additions of $\mathrm{CeO}_{2}(0.3-1.0 \mathrm{wt} \%)$ to Y-TZP were beneficial in enhancing the mechanical properties and hydrothermal ageing resistance of Y-TZP. Sintered samples were used to evaluate the bulk density, Vickers's hardness, Young's modulus, and fracture toughness of the material. $\mathrm{CeO}_{2}$ doped Y-TZPs were sintered at relatively low temperatures $\left(1250^{\circ} \mathrm{C}\right.$ and $\left.1350^{\circ} \mathrm{C}\right)$ retaining high bulk density $(>97 \%$ of theoretical density) and high Young's modulus ( $>200 \mathrm{GPa}$ ) without sacrificing tetragonal phase stability. The optimum level of dopant was found to be at $0.5 \mathrm{wt} \%$ for sintering between $1250^{\circ} \mathrm{C}$ and $1450^{\circ} \mathrm{C}$ using the standard $2 \mathrm{~h}$ holding time cycle, with sintered body exhibiting excellent combination of properties when compared to the undoped ceramics. In this experiment, the addition of $0.5 \mathrm{wt} \%$ recorded a bulk density reading of $5.9 \mathrm{~g} / \mathrm{cm}^{3}$, Vickers hardness value of $13.2 \mathrm{GPa}$, Young's modulus value of $211 \mathrm{GPa}$, and fracture toughness of $6.4 \mathrm{MPam}{ }^{1 / 2}$, respectively, in a temperature range of $1400-1450^{\circ} \mathrm{C}$.
\end{abstract}

\section{Introduction}

Yttria tetragonal zirconia polycrystal (Y-TZP) ceramics serve as an upcoming material for engineering applications and are also considered important for restoration medicine. The excellent mechanical characteristics such as high strength and fracture resistance are attributed to the ceramic's unique ability known as transformation toughening, a stress-induced phase transformation from tetragonal $(\mathrm{t})$ to monoclinic $(\mathrm{m})$ $[1,2]$. The stabilizing effect of yttria $\left(\mathrm{Y}_{2} \mathrm{O}_{3}\right)$ makes it possible for Y-TZP ceramic to be processed in the metastable tetragonal $(t)$ structure. This is essential since the retention of the (t) phase at ambient temperature allows it to transform to the monoclinic $(\mathrm{m})$ structure under external applied stress $[3,4]$.

Despite its outstanding properties, Kobayashi et al. [5] discovered that the Y-TZP ceramics suffer a serious limitation for applications near $250^{\circ} \mathrm{C}$ in moist environment. The findings revealed that the ceramic can suffer a slow, tetragonal to monoclinic phase transformation at the samples surface in a humid atmosphere, followed by microcracking and a major loss in strength known as low temperature degradation (LTD) [6-10]. Since then, experiments have been conducted with Y-TZP in an attempt to understand the basic micromechanisms of the ageing-induced $(\mathrm{t})-(\mathrm{m})$ phase transformation and to suppress the LTD phenomenon [11-19]. Based on research findings, the addition of ceramic oxides $\left(\mathrm{MgO}, \mathrm{Al}_{2} \mathrm{O}_{3}, \mathrm{ZnO}, \mathrm{CaO}\right.$, and $\mathrm{CeO}_{2}$ ) helps overcome if not prevent the low temperature degradation occurrence in Y-TZP ceramics $[9,20-24] . \mathrm{CeO}_{2}$ is generally used to stabilize the tetragonal phase of zirconia and is also known to increase the sintering of glass ceramics and strength and thermal stability [25]. Ce-TZP in contrast to Y-TZP has complete resistance to LTD and higher toughness. Enhancing the moderate Ce-TZP properties would result in the material becoming a primary candidate for biomedical applications which has the requirements in terms of phase stability and long-lasting characteristics in the human body [26].

Fischer and Stawarczyk found that the Ce-TZP/ $/ \mathrm{Al}_{2} \mathrm{O}_{3}$ nanocomposite offers superior mechanical properties compared to conventional Y-TZP. Also, when compared to conventional Y-TZP the flexural strength is in the same range whereas the fracture toughness increases with the addition of ceria [27]. Results from Mangalaraja et al. and Takano et al. investigating the effect of ceria addition both supported 
the statement that ceria increases the fracture toughness of Y-TZP [28, 29].

Kuroda et al. [30] have shown that several reactions occur during sintering with the addition of $\mathrm{CuO}$ which can be beneficial or detrimental for densification of Y-TZP. More recently, tribological studies on 3 mol\% Y-TZP ceramics showed that the addition of $1.8 \mathrm{~mol} \%$ of $\mathrm{CuO}$ led to a reduction of friction coefficient from 0.2 to 0.6 under dry sliding conditions, while another study revealed that the ferromagnetic behaviour of YTZP with enhanced coercivity could be achieved by doping $0.3 \mathrm{~mol} \% \mathrm{NiO}$ in the zirconia matrix [31].

The susceptibility of Y-TZP to low temperature degradation (LTD) is a shortcoming for a material that has excellent mechanical properties and biocompatibility. The addition of cerium oxide, $\mathrm{CeO}_{2}$, makes the material inert to LTD but is counterbalanced by modest strength and hardness, making its usage in biomedical applications limited and difficult. In order to overcome this limitation, the amount of $\mathrm{CeO}_{2}$ addition to Y-TZP is altered along with the sample preparing factors such as sintering methods and temperatures, mixing methods, and the purity of powders used.

\section{Experimental Techniques}

Two commercial type powders were prepared for this experiment: the $3 \mathrm{~mol} \%$ of yttria-stabilized zirconia powder manufactured by Kyoritsu Ltd., Japan, under the code name of $\mathrm{KZ}-3 \mathrm{YF}$ as the base powder and cerium oxide, $\mathrm{CeO}_{2}$, manufactured by Sigma Aldrich, as the dopant. Three different compositions of cerium oxide were mixed with Y-TZP, that is, undoped $0.3 \mathrm{wt} \%, 0.5 \mathrm{wt} \%$, and $1.0 \mathrm{wt} \%$. The powders were mixed using the wet milling method, using zirconia balls as mixing media and ethanol as the mixing medium. The slurry was oven dried at $60^{\circ} \mathrm{C}$ sieved, and the powder was uniaxially pressed at $0.3 \mathrm{MPa}$ into discs and rectangular bars. These samples were then sintered under atmospheric condition at a rate of $10^{\circ} \mathrm{C} / \mathrm{min}$, with temperatures ranging from $1250^{\circ} \mathrm{C}$ to $1450^{\circ} \mathrm{C}$, and a holding time of 2 hours before cooling down to room temperature. The sintering temperatures $1250^{\circ} \mathrm{C}$ to $1450^{\circ} \mathrm{C}$ are used for this research as it is sufficient to retain the tetragonal phase of Y-TZP. Besides that, this temperature range is the optimum temperature range to obtain the high mechanical properties of Y-TZP. Sintered disc samples are then used to determine bulk density and Vickers hardness. Disc samples are polished on a polishing machine with grinding papers of different roughness $(120,240,600$, and 800 $\mathrm{CC}-\mathrm{Cw}$ ) and finally are polished using diamond paste of 6 microns and a polishing cloth.

\section{Characterization}

The bulk density of the sintered samples was measured based on Archimedes' principle, using the water immersion method with a standard Mettler Toledo Balance AG204 densimeter. Polished samples were used to determine Vickers's hardness and fracture toughness $\left(K_{\mathrm{IC}}\right)$ using Vickers's indentation method. An indentation with a force of $9800 \mathrm{~N}$ was applied on the samples and held for 10 seconds. At least three indentations were made and an average value was taken. The fracture toughness was calculated for the measured value obtained using Niihara's [32] formula as stated below:

$$
K_{\mathrm{IC}}=\frac{0.016(E / H)^{1 / 2}}{C^{3 / 2}},
$$

$K_{\text {IC }}$ being the fracture toughness $\left(\mathrm{MPam}^{1 / 2}\right) ; E$ is Young's modulus (GPa), $H$ the Vickers hardness $(\mathrm{GPa})$, and $c$ the crack length $(\mathrm{m})$ measured from the center of indentation. Three measurements were made and the average value was obtained. Young's modulus test was conducted on the rectangular bars by using indentation. The microstructure of the material was evaluated using SEM (scanning electron microscope) whereby the grain structures and grain sizes were determined using the average grain intercept method. The average grain intercept method is used to measure the grain size of a material by drawing randomly positioned line segments on the micrograph, counting the number of times each line segment intersects a grain boundary, and finding the ratio of intercepts to line length.

\section{Results and Discussion}

Figure 1 shows the influence of various $\mathrm{CeO}_{2}$ additions to the bulk density of Y-TZP. The sintering temperature acts as a controlled variable; $\mathrm{CeO}_{2}$-Y-TZP samples are sintered over a temperature range of $1200-1450^{\circ} \mathrm{C}$. A common increasing trend is displayed for all $\mathrm{CeO}_{2}-\mathrm{Y}$-TZP compositions. The addition of $\mathrm{CeO}_{2}$ was beneficial in aiding densification as the increase in density was proportional to the increasing sintering temperature. The figure shows that samples with $\mathrm{CeO}_{2}$ content $>0.3 \mathrm{wt} \%$ achieved much higher values of densities as compared to samples of lower amount and undoped samples. The highest value of density was recorded by the samples with $0.5 \mathrm{wt} \% \mathrm{CeO}_{2}$, which is approximately $97 \%$ of the theoretical value $\left(6.09 \mathrm{~g} / \mathrm{cm}^{3}\right)$ [33]. A significant reduction in density values was observed at higher temperatures, a phenomenon probably attributed to the grain growth. Besides that, the decrease could also be associated with agglomeration of the $\mathrm{CeO}_{2}-\mathrm{Y}-\mathrm{TZP}$ particles during the preparation and sintering processes [34].

The effect of sintering temperatures and $\mathrm{CeO}_{2}$ doped samples on the Vickers hardness of Y-TZP is shown in Figure 2. The undoped sample recorded a hardness value of $9.6 \mathrm{GPa}(978.9 \mathrm{HV})$. When sintered at $1250^{\circ} \mathrm{C}$, the doped samples showed higher hardness values at $1250^{\circ} \mathrm{C}$ but was still below the theoretical value. Generally, all samples showed a similar trend with increasing sintering temperature profiles. The highest value recorded was $13.2 \mathrm{GPa}(1346 \mathrm{HV})$ at a sintering temperature of $1400^{\circ} \mathrm{C}$, before facing a drop in value with further sintering at $1450^{\circ} \mathrm{C}$. Overall, from observation it was found that samples with $0.5 \mathrm{wt} \%$ and $1.0 \mathrm{wt} \%$ dopant addition sintered at temperatures $>1300^{\circ} \mathrm{C}$ achieved hardness values higher than the theoretical Vickers hardness of Y-TZP. The decrease in hardness at high temperatures $\left(>1400^{\circ} \mathrm{C}\right)$ can probably be associated with the increased proportion of transformable tetragonal phase and associated pseudoplasticity [35]. 


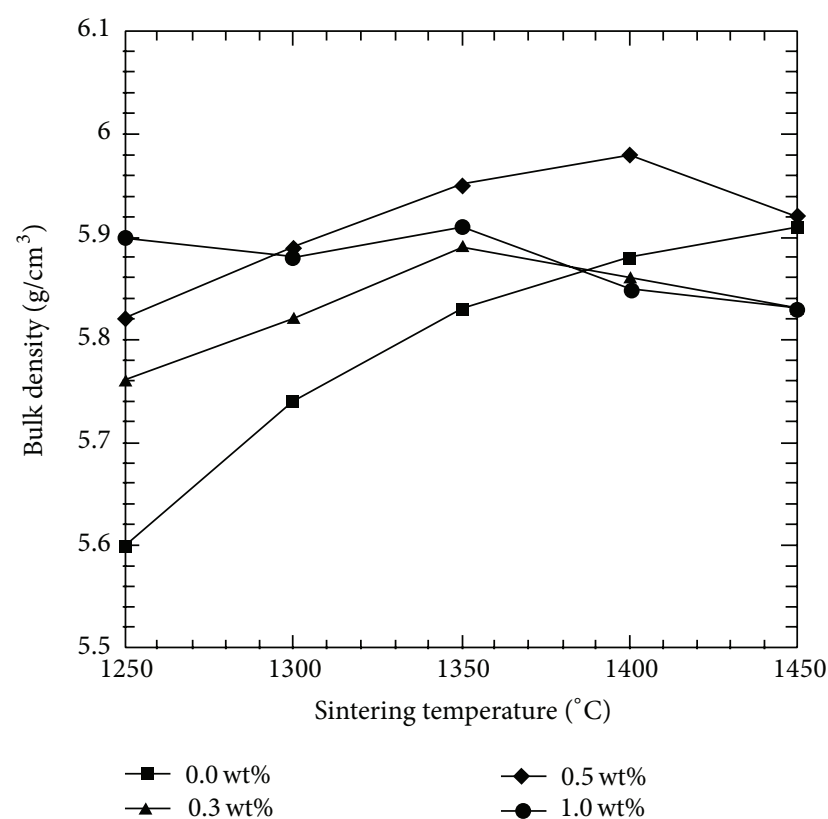

FIGURE 1: Effect of sintering temperature and $\mathrm{CeO}_{2}$ addition to the bulk density of Y-TZP.

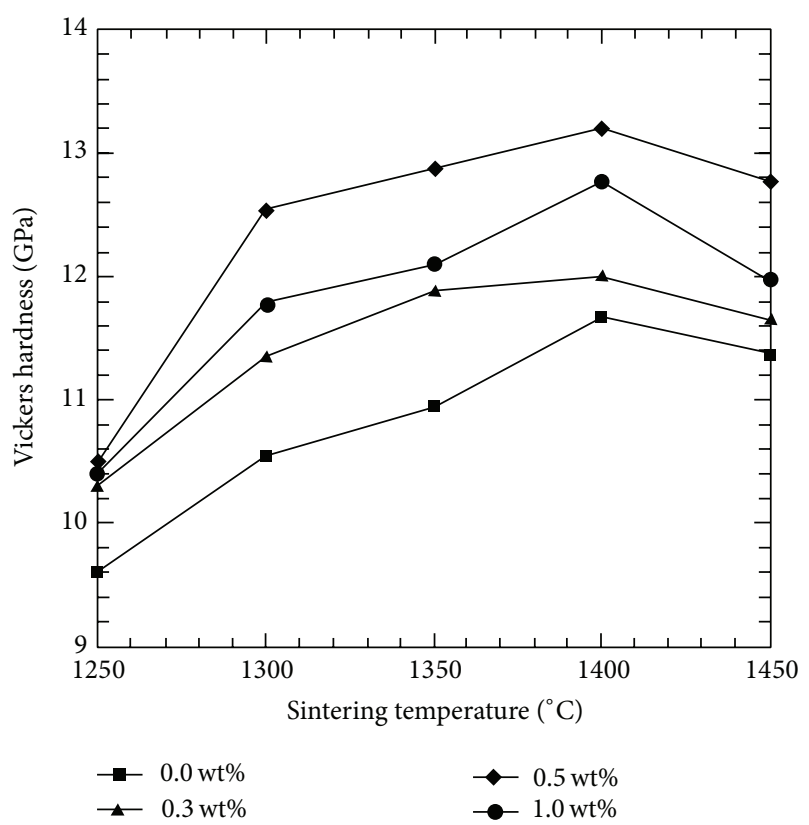

FIGURE 2: Effect of sintering temperature and $\mathrm{CeO}_{2}$ addition to the Vickers hardness of Y-TZP.

The influence of the addition of $\mathrm{CeO}_{2}$ on Young's modulus of the sintered sample is depicted in Figure 3. At $1250^{\circ} \mathrm{C}$, all doped samples reached almost the theoretical value of Young's modulus (210 GPa) [36] whereas the undoped Y-TZP was low $(\sim 177 \mathrm{GPa})$. $E$ values of $\geq 200 \mathrm{GPa}$ were achieved at sintering temperatures $\geq 1300^{\circ} \mathrm{C}$. The $0.3 \mathrm{wt} \% \mathrm{CeO}_{2}-\mathrm{Y}$ TZP doped sample shows a decline in $E$ value from $1350^{\circ} \mathrm{C}$ onward, and in contrast $0.5 \mathrm{wt} \% \mathrm{CeO}_{2}$-Y-TZP kept increasing

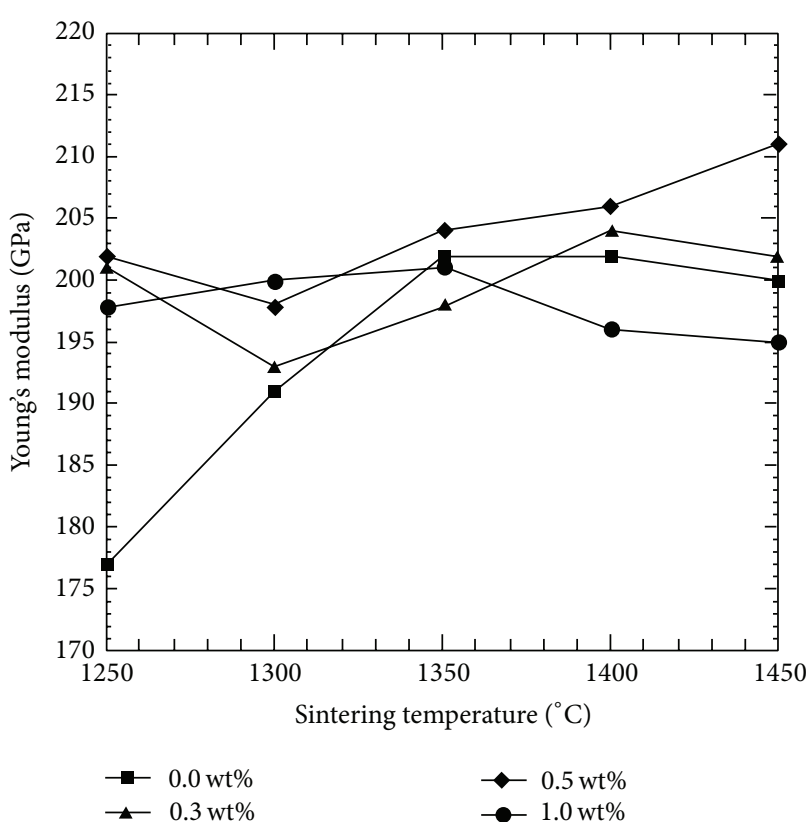

FIGURE 3: Effect of sintering temperature and $\mathrm{CeO}_{2}$ addition to Young's modulus of Y-TZP.

up till $1450^{\circ} \mathrm{C}$ and attained the highest value of $\sim 211 \mathrm{GPa}$. An inversly proportional relationship exists between the bulk density and Young's modulus as a lower density results in a higher elasticity in the material. It can be inferred that the bulk density is an important parameter governing the matrix stiffness of Y-TZP. Similar results were seen in work from other researchers [37, 38].

The influence of the varying amounts of $\mathrm{CeO}_{2}$ and various sintering temperatures on the fracture toughness was seen in Figure 4. It was clearly seen that the addition of $\mathrm{CeO}_{2}$ was beneficial in enhancing the fracture toughness of Y-TZP. At $1250^{\circ} \mathrm{C}$, the undoped sample only reached the fracture toughness value of $4.5 \mathrm{MPam}^{1 / 2}$ while doped samples achieved the higher toughness ranging from $4.8 \mathrm{MPam}^{1 / 2}$ to $5.5 \mathrm{MPam}^{1 / 2}$. All samples showed improvement in toughness when sintered $\geq 1300^{\circ} \mathrm{C}$, except for the $0.3 \mathrm{wt} \%$ doped samples, which in contrast displayed a decreasing trend up till $1450^{\circ} \mathrm{C}$. Sintering at higher temperature $\left(\geq 1300^{\circ} \mathrm{C}\right)$ seems to have an outstanding effect on the fracture toughness of Y-TZP, especially with the addition of $0.5 \mathrm{wt} \% \mathrm{CeO}_{2}$. The highest value of fracture toughness recorded was $6.4 \mathrm{MPam}^{1 / 2}$ for $0.5 \mathrm{wt} \% \mathrm{CeO}_{2}$ addiition at $1400^{\circ} \mathrm{C}$. The high fracture toughness of $\mathrm{CeO}_{2}-$ Y-TZP sample could be attributed to the resistance of the material to crack propagation and also the grain growth [27].

Figures 5 and 6 illustrate the effect of the addition of $0.3 \mathrm{wt} \%$ and $0.5 \mathrm{wt} \% \mathrm{CeO}_{2}$ on the microstructure of the ceramic. The $0.5 \mathrm{wt} \%$ doped sample revealed a microstructure that is more homogenous than the microstructure of the $0.3 \mathrm{wt} \% \mathrm{CeO}_{2}$ doped specimens. The average grain intercept is determined from two of the best samples (polished) with different dopant content sintered at $1400^{\circ} \mathrm{C}$. It is seen that the samples containing $0.3 \mathrm{wt} \% \mathrm{CeO}_{2}$ have a bigger grain size with an average value of $2.13 \mu \mathrm{m}$ whereas the samples with 


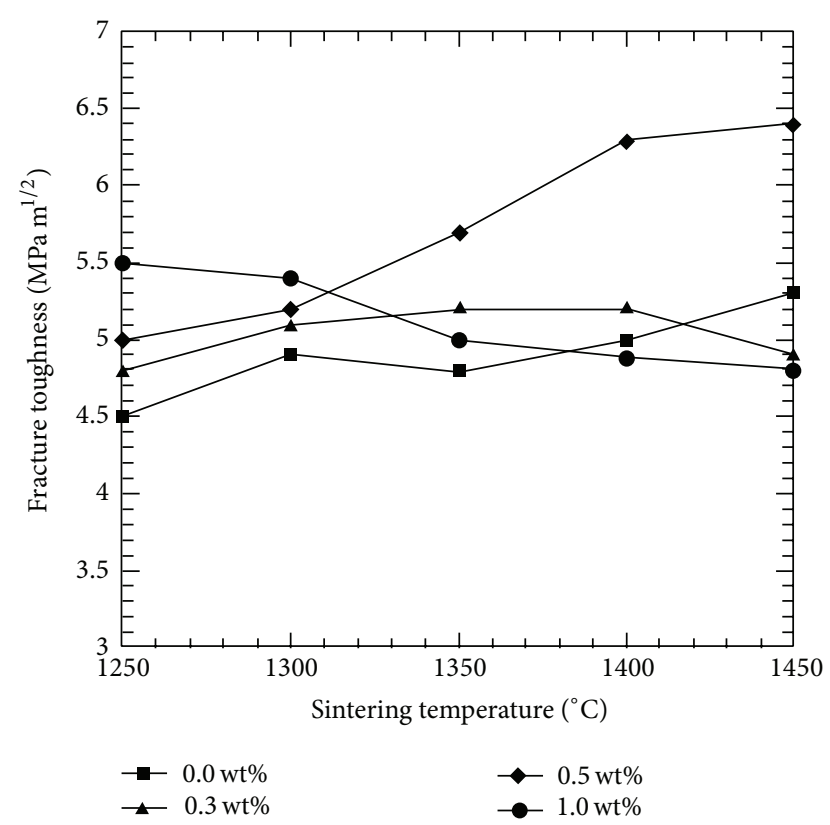

Figure 4: Effect of sintering temperature and $\mathrm{CeO}_{2}$ addition to the fracture toughness of Y-TZP.

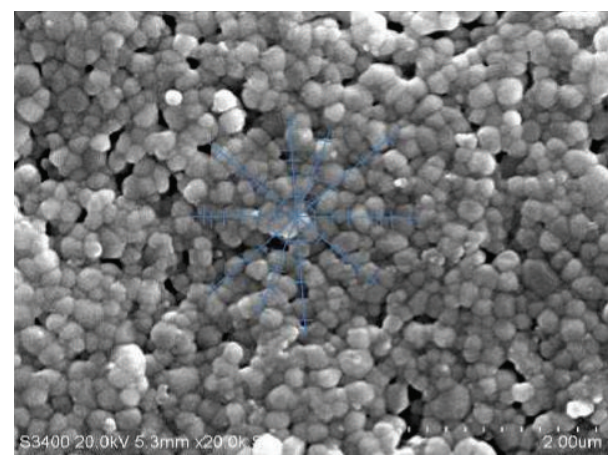

FIGURE 5: SEM imaging of the average grain intercept method for $0.3 \mathrm{wt} \% \mathrm{CeO}_{2}$-Y-TZP at $1400^{\circ} \mathrm{C}$.

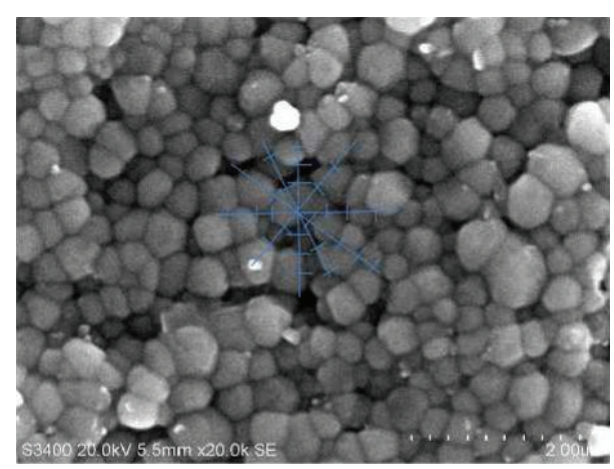

FIGURE 6: SEM imaging of the average grain intercept method for $0.5 \mathrm{wt} \% \mathrm{CeO}_{2}-\mathrm{Y}-\mathrm{TZP}$ at $1400^{\circ} \mathrm{C}$.
$0.5 \mathrm{wt} \% \mathrm{CeO}_{2}$ have a smaller grain size value of $1.586 \mu \mathrm{m}$. Grain growth was proportional to the amount of dopant added.

\section{Conclusion}

The current work shows that adding $\mathrm{CeO}_{2}$ to Y-TZP has proved to be beneficial. The bulk density was found to be higher with a value of $\sim 5.9 \mathrm{~g} / \mathrm{cm}^{3}$ ( $\sim 97 \%$ of the theoretical density), with the addition of up to $0.5 \mathrm{wt} \% \mathrm{CeO}_{2}$ when sintered at $1400^{\circ} \mathrm{C}$. Doping $\mathrm{CeO}_{2}$ into Y-TZP also enhanced other mechanical properties. All samples with $0.5 \mathrm{wt} \% \mathrm{CeO}_{2}$ produced the highest values for mechanical properties; the Vickers hardness was increased to $\sim 13.2 \mathrm{GPa}$; Young's modulus was enhanced to $\sim 211 \mathrm{GPa}$; fracture toughness was increased to $\sim 6.4 \mathrm{MPam}^{1 / 2}$. Also, sintering temperature had an important role in determining the mechanical properties and microstructure of the material as most increment in values occurred at temperatures $\geq 1300^{\circ} \mathrm{C}$.

\section{Conflict of Interests}

The authors declare that there is no conflict of interests regarding the publication of this paper.

\section{References}

[1] G. A. Gogotsi, V. I. Galenko, S. P. Mudrik, B. I. Ozersky, V. V. Khvorostyany, and T. A. Khristevich, "Fracture behaviour of YTZP ceramics: new outcomes," Ceramics International, vol. 36, no. 1, pp. 345-350, 2010.

[2] A. H. A. Sabrah, N. B. Cook, P. Luangruangrong, A. T. Hara, and M. C. Bottino, "Full-contour Y-TZP ceramic surface roughness effect on synthetic hydroxyapatite wear," Dental Materials, vol. 29, no. 6, pp. 666-673, 2013.

[3] P. M. Kelly and L. R. F. Rose, "The martensitic transformation in ceramics-its role in transformation toughening," Progress in Materials Science, vol. 47, no. 5, pp. 463-557, 2002.

[4] K. Matsui, H. Yoshida, and Y. Ikuhara, "Grain-boundary structure and microstructure development mechanism in 2-8 mol\% yttria-stabilized zirconia polycrystals," Acta Materialia, vol. 56, no. 6, pp. 1315-1325, 2008.

[5] K. Kobayashi, H. Kuwajima, and T. Masaki, "Phase change and mechanical properties of $\mathrm{ZrO}_{2}-\mathrm{Y}_{2} \mathrm{O}_{3}$ solid electrolyte after ageing," Solid State Ionics, vol. 3-4, pp. 489-493, 1981.

[6] C. Schröder, A. Renz, C. Koplin, and A. Kailer, "Assessment of low-temperature degradation of Y-TZP ceramics based on Raman-spectroscopic analysis and hardness indentation," Journal of the European Ceramic Society, vol. 34, no. 16, pp. 43114319, 2014.

[7] M. Keuper, K. Eder, C. Berthold, and K. G. Nickel, "Direct evidence for continuous linear kinetics in the low-temperature degradation of Y-TZP," Acta Biomaterialia, vol. 9, no. 1, pp. 4826-4835, 2013.

[8] F. Zhang, K. Vanmeensel, M. Inokoshi et al., "3Y-TZP ceramics with improved hydrothermal degradation resistance and fracture toughness," Journal of the European Ceramic Society, vol. 34, no. 10, pp. 2453-2463, 2014.

[9] Z.-K. Wu, N. Li, C. Jian, W.-Q. Zhao, and J.-Z. Yan, "Low temperature degradation of $\mathrm{Al}_{2} \mathrm{O}_{3}$-doped 3Y-TZP sintered at 
various temperatures," Ceramics International, vol. 39, no. 6, pp. 7199-7204, 2013.

[10] M. Cattani-Lorente, S. S. Scherrer, P. Ammann, M. Jobin, and H. W. A. Wiskott, "Low temperature degradation of a Y-TZP dental ceramic," Acta Biomaterialia, vol. 7, no. 2, pp. 858-865, 2011.

[11] P. Kohorst, L. Borchers, J. Strempel et al., "Low-temperature degradation of different zirconia ceramics for dental applications," Acta Biomaterialia, vol. 8, no. 3, pp. 1213-1220, 2012.

[12] L. Borchers, M. Stiesch, F.-W. Bach et al., "Influence of hydrothermal and mechanical conditions on the strength of zirconia," Acta Biomaterialia, vol. 6, no. 12, pp. 4547-4552, 2010.

[13] F. Egilmez, G. Ergun, I. Cekic-Nagas, P. K. Vallittu, and L. V. J. Lassila, "Factors affecting the mechanical behavior of Y-TZP," Journal of the Mechanical Behavior of Biomedical Materials, vol. 37, pp. 78-87, 2014.

[14] J. Valle, A. Mestra, F. G. Marro, and M. Anglada, "Mechanical properties and resistance to low temperature degradation of surface nitrided 3Y-TZP," Journal of the European Ceramic Society, vol. 33, no. 15-16, pp. 3145-3155, 2013.

[15] H. P. Papanagiotou, S. M. Morgano, R. A. Giordano, and R. Pober, "In vitro evaluation of low-temperature aging effects and finishing procedures on the flexural strength and structural stability of Y-TZP dental ceramics," The Journal of Prosthetic Dentistry, vol. 96, no. 3, pp. 154-164, 2006.

[16] J. Chevalier, "What future for zirconia as a biomaterial?" Biomaterials, vol. 27, no. 4, pp. 535-543, 2006.

[17] T. Kosmač, Č. Oblak, and L. Marion, "The effects of dental grinding and sandblasting on ageing and fatigue behavior of dental zirconia (Y-TZP) ceramics," Journal of the European Ceramic Society, vol. 28, no. 5, pp. 1085-1090, 2008.

[18] M. Cattani-Lorente, S. S. Scherrer, S. Durual et al., "Effect of different surface treatments on the hydrothermal degradation of a 3Y-TZP ceramic for dental implants," Dental Materials, 2014.

[19] N. Masahiro, N. Kurizoe, Y. Okamoto, and A. Ueno, “Transformation-induced plastic deformation in Ce-TZP/alumina nanocomposite generated during fatigue tests at room temperature," Journal of the European Ceramic Society, vol. 34, no. 16, pp. 4337-4345, 2014.

[20] X. Guo and J. He, "Hydrothermal degradation of cubic zirconia," Acta Materialia, vol. 51, no. 17, pp. 5123-5130, 2003.

[21] X. Guo and T. Schober, "Water incorporation in tetragonal zirconia," Journal of the American Ceramic Society, vol. 87, no. 4, pp. 746-748, 2004.

[22] V. Lughi and V. Sergo, "Low temperature degradation -agingof zirconia: a critical review of the relevant aspects in dentistry," Dental Materials, vol. 26, no. 8, pp. 807-820, 2010.

[23] J. R. Kelly and I. Denry, "Stabilized zirconia as a structural ceramic: an overview," Dental Materials, vol. 24, no. 3, pp. 289298, 2008.

[24] L. Hallmann, P. Ulmer, E. Reusser, M. Louvel, and C. H. F. Hämmerle, "Effect of dopants and sintering temperature on microstructure and low temperature degradation of dental YTZP-zirconia," Journal of the European Ceramic Society, vol. 32, no. 16, pp. 4091-4104, 2012.

[25] O. Gunduz, C. Gode, Z. Ahmad et al., "Preparation and evaluation of cerium oxide-bovine hydroxyapatite composites for biomedical engineering applications," Journal of the Mechanical Behavior of Biomedical Materials, vol. 35, pp. 70-76, 2014.

[26] M. Nawa, K. Yamada, and N. Kurizoe, "Effect of the t-m transformation morphology and stress distribution around the crack path on the measured toughness of zirconia ceramics: a case study on Ce-TZP/alumina nanocomposite," Journal of the European Ceramic Society, vol. 33, no. 3, pp. 521-529, 2013.

[27] J. Fischer and B. Stawarczyk, "Compatibility of machined Ce$\mathrm{TZP} / \mathrm{Al}_{2} \mathrm{O}_{3}$ nanocomposite and a veneering ceramic," Dental Materials, vol. 23, no. 12, pp. 1500-1505, 2007.

[28] R. V. Mangalaraja, B. K. Chandrasekhar, and P. Manohar, "Effect of ceria on the physical, mechanical and thermal properties of yttria stabilized zirconia toughened alumina," Materials Science and Engineering A, vol. 343, no. 1-2, pp. 71-75, 2003.

[29] T. Takano, A. Tasaka, M. Yoshinari, and K. Sakurai, "Fatigue strength of $\mathrm{Ce}-\mathrm{TZP} / \mathrm{Al}_{2} \mathrm{O}_{3}$ nanocomposite with different surfaces," Journal of Dental Research, vol. 91, no. 8, pp. 800-804, 2012.

[30] K. Kuroda, H. Saka, S. Iio, M. Watanabe, and T. Imura, “Tetragonal-to-monoclinic transformation in $\mathrm{ZrO}_{2}-\mathrm{Y}_{2} \mathrm{O}_{3}$ ceramics," in Proceedings of the International Conference on Martensitic Transformations, pp. 1161-1166, The Japan Institute of Metals, 1986.

[31] T. Shigematsu, Y. Nakao, and N. Nakanishi, "Effect of water on the tetragonal tomonoclinic phase transition of $\mathrm{ZrO}_{2}$ with $\mathrm{Y}_{2} \mathrm{O}_{3}$," MRS Intl. Mtg. on Adv. Mats, vol. 9, pp. 549-554, 1989.

[32] J. Chevalier, J. Loh, L. Gremillard, S. Meille, and E. Adolfson, "Low-temperature degradation in zirconia with a porous surface," Acta Biomaterialia, vol. 7, no. 7, pp. 2986-2993, 2011.

[33] S. Ramesh, M. Amiriyan, S. Meenaloshini et al., "Densification behaviour and properties of manganese oxide doped Y-TZP ceramics," Ceramics International, vol. 37, no. 8, pp. 3583-3590, 2011.

[34] N. Soltani, M. I. Pech-Canul, and A. Bahrami, "Effect of 10Ce$\mathrm{TZP} / \mathrm{Al}_{2} \mathrm{O}_{3}$ nanocomposite particle amount and sintering temperature on the microstructure and mechanical properties of $\mathrm{Al} /\left(10 \mathrm{Ce}-\mathrm{TZP} / \mathrm{Al}_{2} \mathrm{O}_{3}\right)$ nanocomposites," Materials and Design, vol. 50, pp. 85-91, 2013.

[35] S. N. B. Hodgson and J. Cawley, "The effect of titanium oxide additions on the properties and behaviour of Y-TZP," Journal of Materials Processing Technology, vol. 119, no. 1-3, pp. 112-116, 2001.

[36] Zirconium Oxide, $\mathrm{ZrO}_{2}$ Ceramic Properties, Accuratus, http:// accuratus.com/zirc.html.

[37] S. Ramesh, S. Meenaloshini, C. Y. Tan, W. J. K. Chew, and W. D. Teng, "Effect of manganese oxide on the sintered properties and low temperature degradation of Y-TZP ceramics," Ceramics International, vol. 34, no. 7, pp. 1603-1608, 2008.

[38] S. N. B. Hodgson, J. Cawley, and M. Clubley, "The role of $\mathrm{SiO}_{2}$ impurities in the microstructure and properties of Y-TZP," Journal of Materials Processing Technology, vol. 86, no. 1-3, pp. 139-145, 1998. 

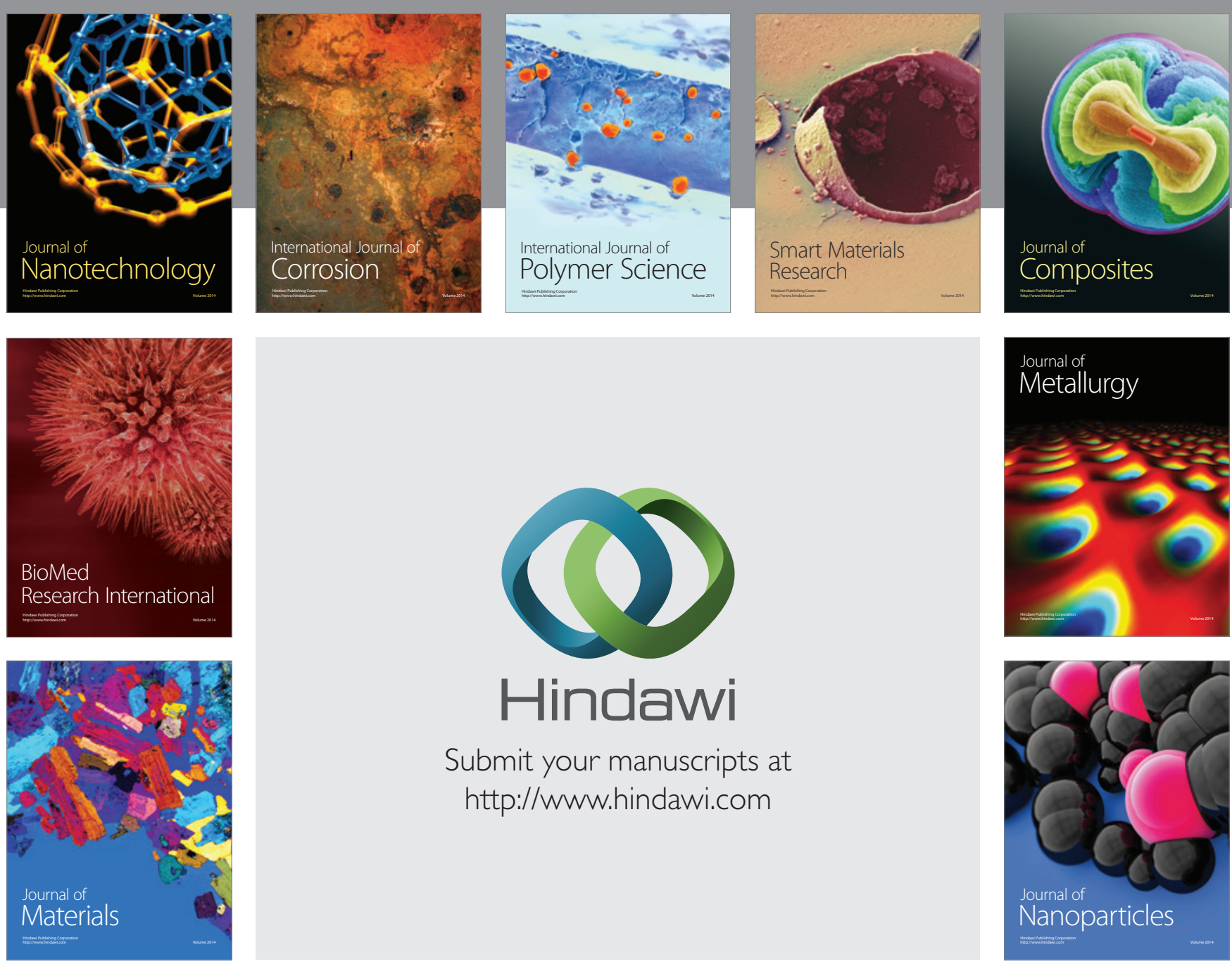

Submit your manuscripts at http://www.hindawi.com
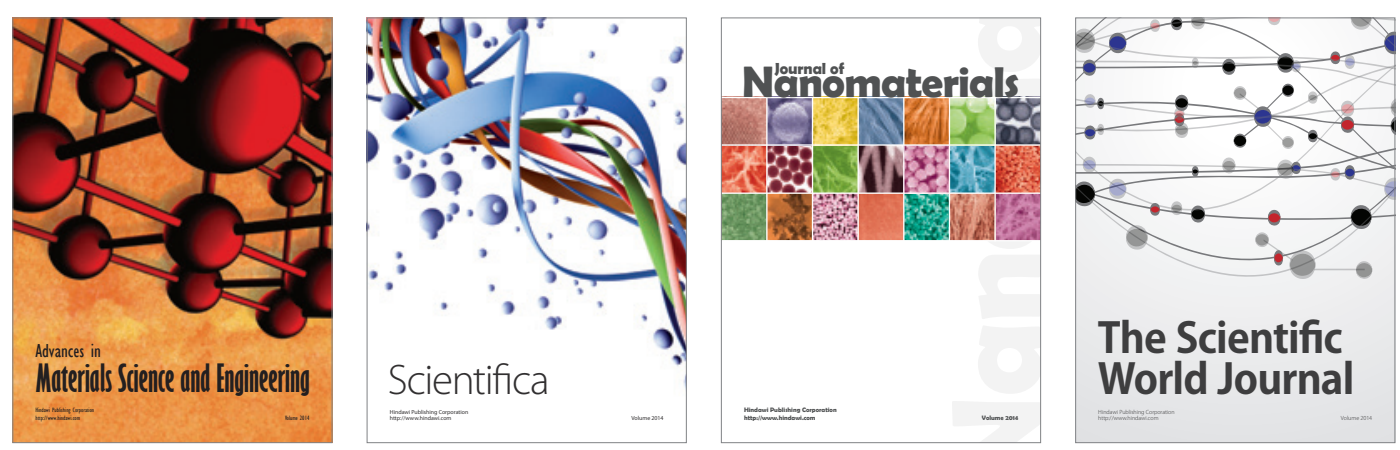

\section{The Scientific World Journal}
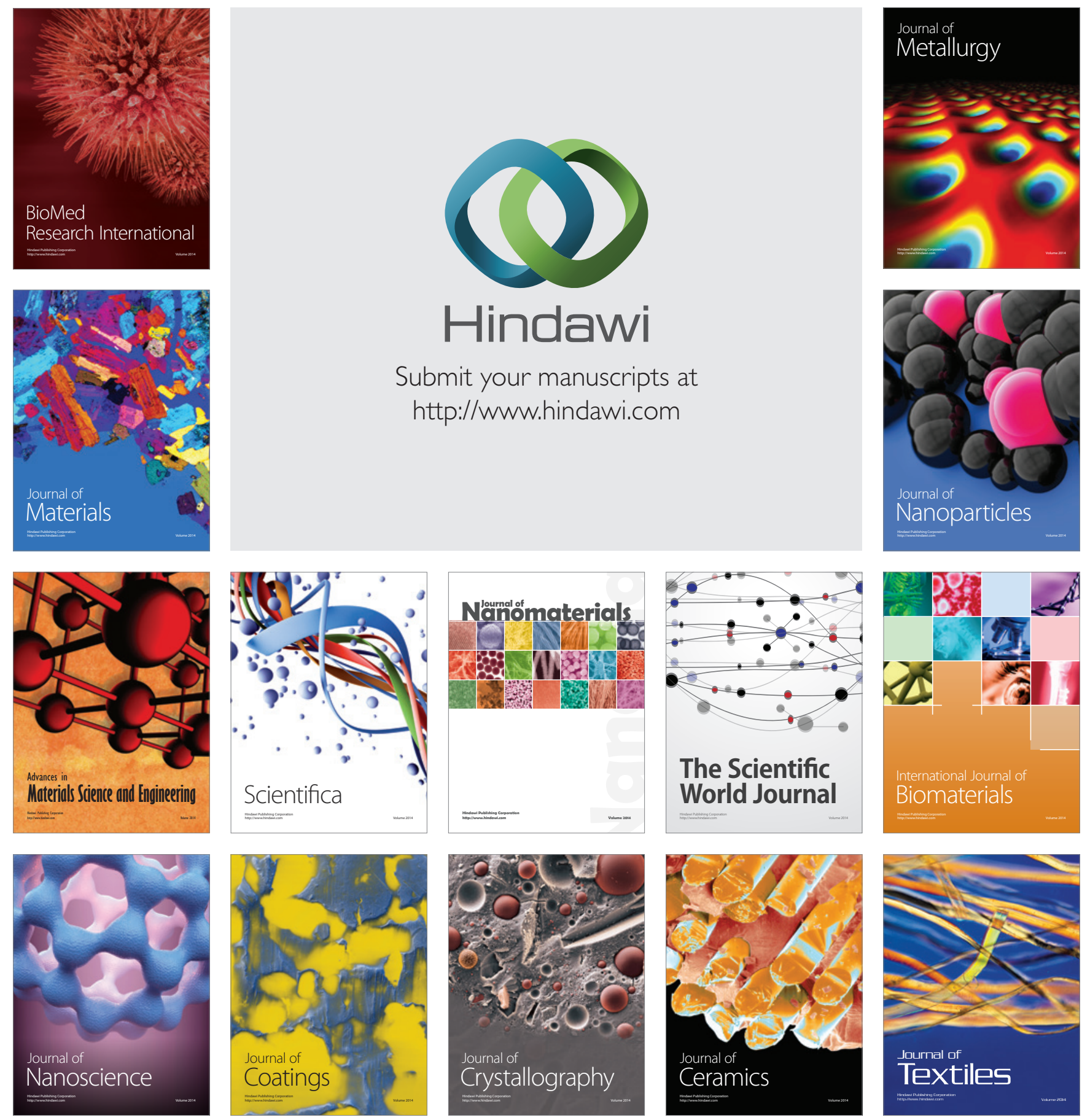